\title{
DIFFERENCE FREQUENCY GENERATION BETWEEN THE OUTPUT WAVES OF THE PP-MgO : LN OPTICAL PARAMETRIC OSCILLATOR
}

\author{
V. Vaičikauskas ${ }^{\text {a }}$, M. Kaučikas ${ }^{\mathrm{a}, \mathrm{b}}$, and Z. Kuprionis ${ }^{\mathrm{b}}$ \\ a Institute of Physics, Savanoriu 231, LT-02300 Vilnius, Lithuania \\ E-mail: m.kaucikas@ekspla.com \\ b EKSPLA, Savanoriu 231, LT-02300 Vilnius, Lithuania
}

Received 10 July 2008; accepted 18 September 2008

\begin{abstract}
The difference frequency generation in the $\mathrm{AgGaSe}_{2}$ crystal between output waves of a periodically poled $\mathrm{MgO}$ doped lithium niobate (PP-MgO : $\mathrm{LN}$ ) optical parametric oscillator (OPO) is described in this paper. The wavelength of the generated radiation is tunable from 6 to $13 \mu \mathrm{m}$ with the average generated power in the range of several microwatts. The set-up allows a rapid tuning of the wavelength in the limited region of spectra without changing the temperature of the PP-MgO : LN crystal. A typical spectral linewidth of $5 \mathrm{~cm}^{-1}$ makes this source suitable for spectrometry of complex molecules under atmospheric conditions. The measured spectrum of the acetone vapour is presented to confirm this fact.
\end{abstract}

Keywords: nonlinear optics, optical frequency converters, infrared sources

PACS: 42.65.-k, 42.79.Nv, 42.72.Ai

\section{Introduction}

The middle infrared (mid-IR) radiation region of spectra $(8-12 \mu \mathrm{m})$ provides several important benefits for laser spectroscopy. First, it is the region of the fundamental vibrations. The absorption is several times stronger than in the near-IR or visible region and complex molecules have their characteristic absorption features here. Another benefit especially important for remote sensing applications is that the transparency window of the atmosphere is located in this region. But the choice of compact continuously tunable mid-IR laser sources is limited.

Only with the advent of diode pumped lasers and periodically poled lithium niobate (PPLN) the compact high repetition rate mid-IR systems became feasible. But the operation of devices solely based on the PPLN crystal is limited by the transparency at $4.7 \mu \mathrm{m}$, so additional cascade of frequency conversion must be applied to reach the mid-IR region.

Difference frequency generation (DFG) has been applied to mid-IR generation for several decades and recently this method has been used with output of the optical parametric oscillators based on periodically poled crystals and pumped by the Nd: YAG laser. DFG between the PPLN optical parametric oscillator (OPO) signal beam and the first harmonic of the Nd: YAG laser [1] as well as mixing of outputs of two separate PPLN OPOs $[2,3]$ have been demonstrated. A complex system with intracavity DFG in the near-IR region and sequential DFG generation in mid-IR have also been reported [4]. But the optical set-ups of the above systems are fairly complicated and this fact sets a limit on how compact the source could be.

The most compact system would include DFG between the signal and idler waves of the same OPO. This approach has been successfully applied with bulk LN and $\mathrm{KTP}\left(\mathrm{KTiOPO}_{4}\right)$ OPOs in $\mathrm{AgGaSe}$ and $\mathrm{AgGaS}_{2}$ crystals (see [5-8]). As far as periodically poled crystals are concerned, successful DFG in $\mathrm{AgGaS}_{2}$ between PPLN OPO output waves was reported by Haidar et al. [9]. Continuous tuning from 9.4 to $10.5 \mu \mathrm{m}$ with pulse energies around $3 \mu \mathrm{J}$ was demonstrated. But the spectrum of the generated radiation was broad as no attempt to narrow it was made.

In this paper we describe a compact high repetition rate mid-IR laser source that consists of a narrow spectrum $\mathrm{MgO}$ doped PPLN (PP-MgO : LN) OPO and DFG section with the $\mathrm{AgGaSe}_{2}$ crystal pumped by the output waves of the OPO. 


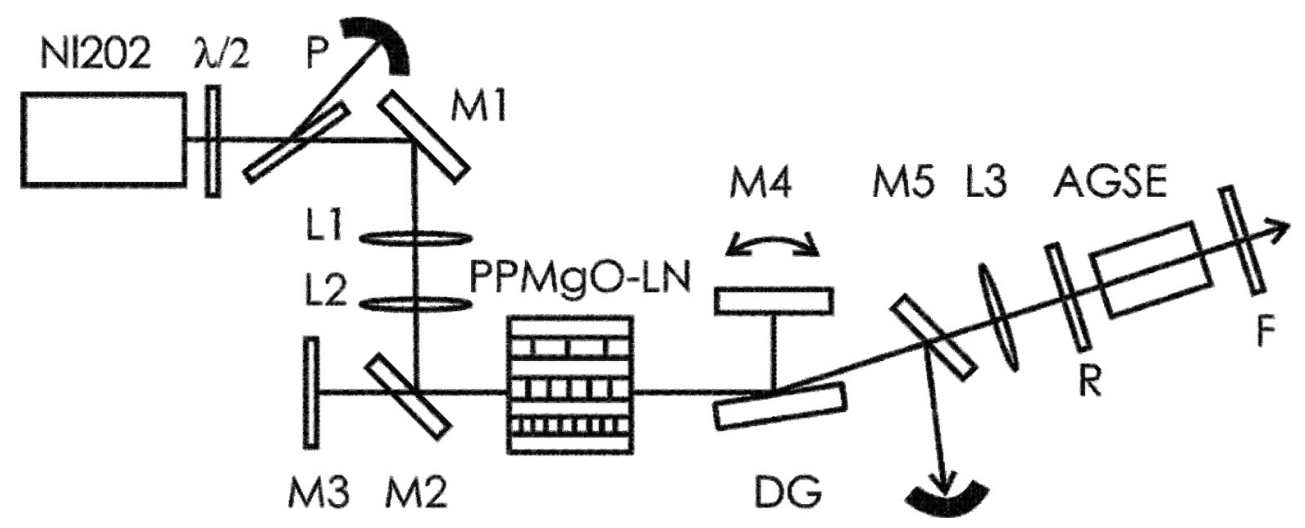

Fig. 1. The set-up of DFG system. Here $D G$ is diffraction grating, $M 1-M 5$ are mirrors, $L 1-L 3$ lenses, $P$ polarizer, $R$ quartz polarization rotator, $A G S E \mathrm{AgGeSe}_{2}$ crystal, and $F$ interference filter.

\section{Experimental set-up}

The primary pump laser source was a commercial diode pumped Nd:YAG nanosecond laser (NL202, EKSPLA). It produced pulses shorter than $9 \mathrm{~ns}$ with energies up to $1.8 \mathrm{~mJ}$ and the repetition rate tunable from 1 to $1000 \mathrm{~Hz}$. The set-up of the system is presented in Fig. 1. The intensity of the beam reaching the PP-MgO: LN crystal can be changed by means of the $\lambda / 2$ plate and the polarizer $\mathrm{P}$ or by changing the current of the pump diode. As the diameter of the beam was slightly smaller than $1 \mathrm{~mm}$ and the width of the $\mathrm{PP}-\mathrm{MgO}: \mathrm{LN}$ crystal was exactly $1 \mathrm{~mm}$, the lenses $L 1$ and $L 2$ were used to change the location of the beam waist, but not the diameter.

The PP-MgO : LN crystal $\left(1.0 \times 16.0 \times 30.0 \mathrm{~mm}^{3}\right)$ had twelve gratings, each $1 \mathrm{~mm}$ in width, with periods from 26 to $31.5 \mu \mathrm{m}$. Only the last grating with the longest period was used in this work. The crystal was placed in an oven which was connected to the controller. The temperature could be changed from room temperature to $200{ }^{\circ} \mathrm{C}$. There was a gold mirror at one end of the cavity and a grazing incidence grating - rotating mirror combination similar to that described in [10] was used in place of the output coupler. While the $600 \mathrm{~mm}^{-1}$ groove gold grating was held stable with the angle of incidence close to 90 degrees, the gold mirror (M4 in Fig. 1) was mounted on a rotating table with a stepper motor and its position was controlled by the computer. The zero order of diffraction was used for output of the radiation and the part of the first diffraction order was reflected back to the cavity, resulting in the narrowed spectrum of the generated radiation. The pump radiation was introduced into the $\mathrm{PP}-\mathrm{MgO}: \mathrm{LN}$ OPO by means of the folding dichroic mirror. This mirror was highly reflective at the pump radiation wavelength, but anti-reflection coated for the $1.3-4.8 \mu \mathrm{m}$ range. A sep- arating mirror was used to reflect the pump out and to separate it from generated radiation.

During the quasi-phase-matched interaction in the $\mathrm{PP}-\mathrm{MgO}: \mathrm{LN}$ crystal, the polarizations of the signal and idler waves are the same as the polarization of the pump. But for the type I DFG in the $\mathrm{AgGaSe}_{2}$ the interacting waves must be of orthogonal polarizations: the signal wave must be polarized in the extraordinary direction and the idler in the ordinary direction. Therefore, a special phase plate must be used to rotate polarization of one wave, but to leave the polarization of the other intact. We used calculations presented in [6] for such a phase plate and a $470 \mu \mathrm{m}$ thick quartz plate was made which rotated the polarization of the idler wave by 90 degrees, but the polarization of the signal wave remained unchanged. This phase plate was optimized for the $2.5 \mu \mathrm{m}$ wavelength, but we did not observe a significant decrease in its performance in the whole tuning range from 2.3 to $2.6 \mu \mathrm{m}$ used in this work.

The DFG stage was based on the $\mathrm{AgGaSe}_{2}$ crystal $\left(\Theta=54^{\circ}, \phi=45^{\circ}, 10 \times 8 \times 20 \mathrm{~mm}^{3}\right)$. The crystal cut angle was optimized for type I interaction with the $1.57 \mu \mathrm{m}$ pump wavelength.

After passing the phase plate, the output of the OPO was focused by a lens $(f=200 \mathrm{~mm})$ to an $\mathrm{AgGaSe}_{2}$ crystal. This produced the beam spot size of $1 \mathrm{~mm}$ with the maximum intensity reaching $2 \mathrm{MW} / \mathrm{cm}^{2}$. This value is much smaller than the optical damage threshold of the $\mathrm{AgGaSe}_{2}$ crystal which according to different sources is in the $20-30 \mathrm{MW} / \mathrm{cm}^{2}$ range, so this set-up leaves room for an additional increase in the DFG pump intensity.

We used bandpass interference filters to separate the DFG wavelength from the pump wavelengths. The DFG signal was recorded with the thermo-electrically cooled MCT detector (PCI-2TE-12, Vigo System S.A., $D^{*}=7.5 \cdot 10^{8} \mathrm{~cm} \mathrm{~Hz}^{1 / 2} \mathrm{~W}^{-1}$, time constant $\left.5 \mathrm{~ns}\right)$. 


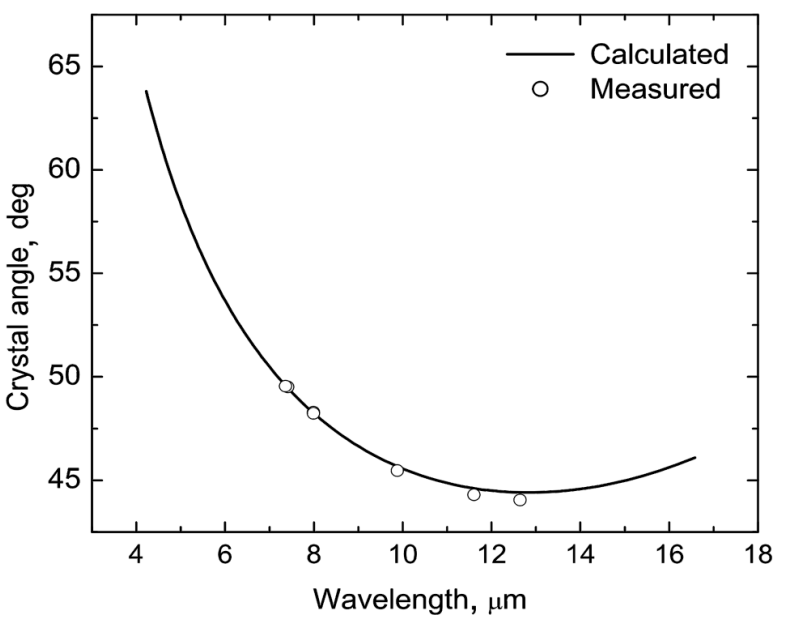

Fig. 2. The tuning curve of the $\mathrm{AgGaSe}_{2}$ crystal. Values calculated using the Sellmeier coefficients from [11].

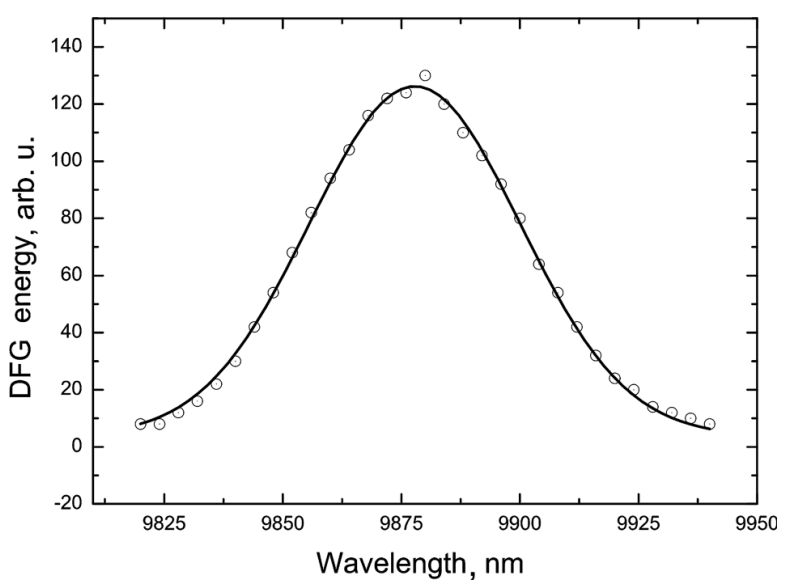

Fig. 3. The measured spectrum of the DFG radiation and Gaussian fit of the data (resulting bandwidth $\mathrm{d} \nu=5.3 \mathrm{~cm}^{-1}$ ).

Spectral measurements were performed with the monochromator (MDR-4 by LOMO, 75 groves/mm grating).

\section{Results}

The PP-MgO:LN OPO signal wavelength varied from 1.96 to $1.80 \mu \mathrm{m}$ and the corresponding idler wavelength from 2.32 to $2.60 \mu \mathrm{m}$ with the temperature change of the PP-MgO : LN crystal from 135 to $190^{\circ} \mathrm{C}$. The signal and idler pulse energy combined was around $50 \mu \mathrm{J}$ in the whole tuning range. We could only estimate the width of the spectrum of the generated radiation due to limited spectral resolution of our monochromator. We believe that the linewidth of the signal radiation is smaller than $1 \mathrm{~cm}^{-1}$ and that of the idler radiation smaller than $2 \mathrm{~cm}^{-1}$, which is consistent with values reported in [10].

The tuning curve of the $\mathrm{AgGaSe}_{2}$ crystal is presented in Fig. 2. The measured values are compared to the values which were calculated from the Sellmeier coefficients from [11]. Slight discrepancy is observed in the long wavelength region. We only calibrated the DFG wavelength in the $7-13 \mu \mathrm{m}$ range because this range is the most interesting for spectroscopic applications. The interference filters had an unwanted narrow, but deep absorption line in the neighbourhood of $9 \mu \mathrm{m}$ that caused a gap in tuning range of the DFG source. But this gap could be easily avoided with more suitable bandpass filters.

The typical spectral bandwidth of the DFG radiation was $5 \mathrm{~cm}^{-1}$ in the whole tuning range. This value is smaller than those previously reported for experiments of DFG with OPO pumping [6,9]. The spectrum of the DFG radiation at $9.88 \mu \mathrm{m}$ is presented in Fig. 3 .

We measured the acceptance angle of the $\mathrm{AgGaSe}_{2}$ crystal at several wavelengths. The measured curve for the $8 \mu \mathrm{m}$ wavelength is presented in Fig. 4 along with the corresponding curve calculated using the Sellmeier coefficients. Small discrepancy was observed between the measured and calculated values. The measured acceptance angle was $3.5 \mathrm{mrad}$ and the calculated one $2.8 \mathrm{mrad}$. Much better coincidence of the calculations and experiment was observed at longer wavelengths.

We estimated that the energy of DFG pulses was at the $\mathrm{nJ}$ level. The corresponding average power of the source was several $\mu \mathrm{W}$. The efficiency of the DFG was very low $-0.001 \%$, especially compared to the theoretical value of $1 \%$ in nondepleted pump infinite plane wave approximation [12]. We would like to note that the source was built for subsequent spectroscopic applications and extreme care was taken to avoid surface damage of the PP-MgO : LN nonlinear crystal. The crystal was pumped at intensities reaching $50 \mathrm{MW} / \mathrm{cm}^{2}$. Increasing this intensity would also significantly increase

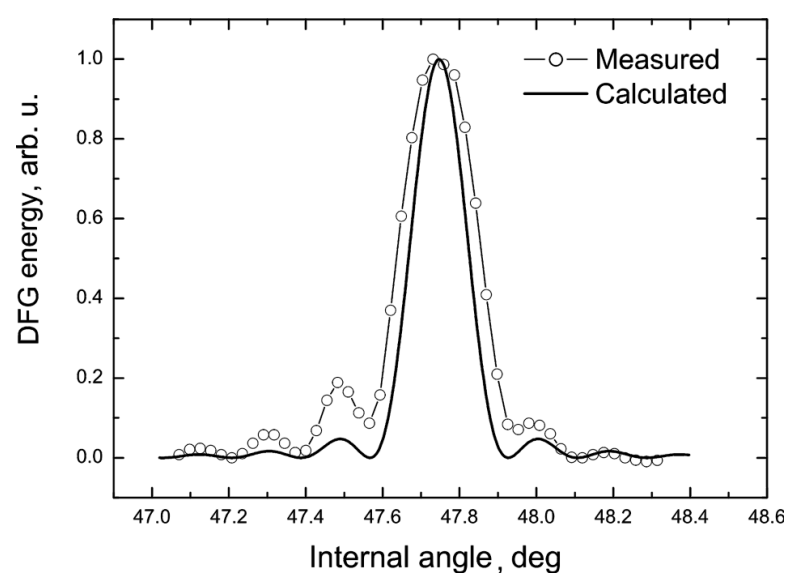

Fig. 4. Measured (points) and calculated (solid line) angular acceptance curves of the $\mathrm{AgGaSe}_{2}$ crystal for the $8 \mu \mathrm{m}$ DFG wavelength. 


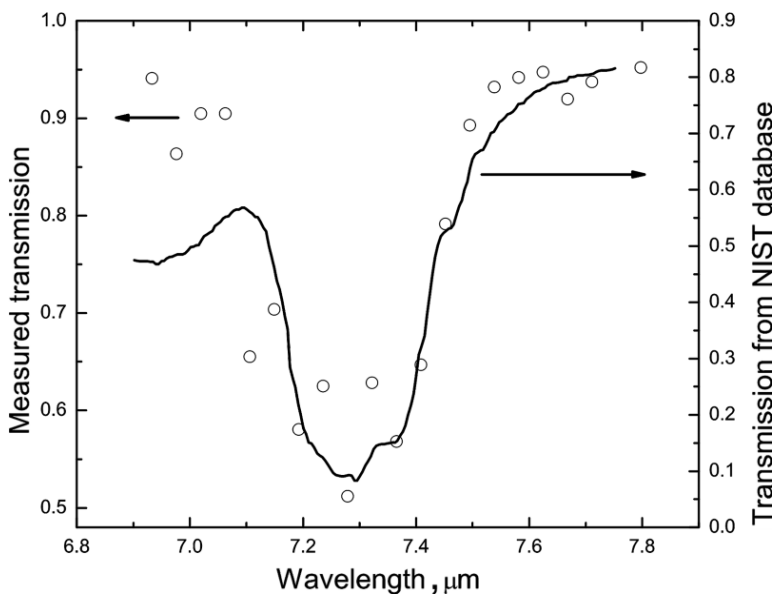

Fig. 5. Transmittance of the acetone vapour measured with the DFG source (left). For comparison a similar spectrum from NIST database [13] is presented (right, measured with resolution of $\left.4 \mathrm{~cm}^{-1}\right)$.

the energy of the DFG radiation, but at the risk of damaging the crystal.

Besides, the walk-off distance is $8.8 \mathrm{~cm}$ at $8 \mu \mathrm{m}$ for the DFG crystal, so further reduction of beam diameters is possible. But further focusing can lead to increased divergence of the pump and signal wavelengths. Moreover, if the divergence is higher than the acceptance angle, the conversion efficiency will be limited. Thus, the best way of increasing the conversion efficiency would be using higher pump energies.

To demonstrate the suitability of the source for spectroscopic measurements, the absorption spectrum of the acetone vapour was recorded. A low concentration of acetone vapour was allowed to flow into the $10 \mathrm{~cm}$ gas cell for a short period of time and the cell was closed. The absorption spectrum of the vapour was recorded without changing the temperature of the PP-MgO : LN crystal. Only the grating mirror and the $\mathrm{AgGaSe}_{2}$ crystal angle were tuned. The average of the 128 shots was taken and the step of $40 \mathrm{~nm}$ was used. This value is close to the spectral bandwidth of the radiation. The resulting spectrum is presented in Fig. 5. The acetone spectrum taken from NIST [13] spectral database is presented in the same figure for comparison. The reference spectrum was measured for higher concentration of the vapour, so the scale was adjusted for clarity. The fluctuations of the DFG signal resulted in the noisy measured spectrum, but the noise could be easily reduced by using the reference detector.

\section{Discussion}

One of the most serious drawbacks of all systems based on PPLN is a very slow temperature tuning. Then long measurement times, sometimes up to several hours $[14,15]$, are needed in spectroscopic applications. If the DFG between the output waves of the PPLN OPO is used, the PPLN OPO wavelength change needed for the DFG wavelength to cover a several micrometre region is small, but still requires time for the temperature to change and stabilize. The attempt to address this issue was made in [9]. A special electro-optically tunable PPLN crystal was manufactured and by applying high voltage allowed the tuning of generated wavelengths. Yet this source had no spectrum narrowing system. In our set-up, it is possible to change the signal and idler wavelengths of the PP-MgO : LN OPO by moving the grating mirror. Together with adjustment of the $\mathrm{AgGaSe}_{2}$ crystal angle this allows variation of DFG wavelength in a reasonable range without loss of generated power. A typical situation is presented in Fig. 6 . A tuning range of around $1 \mu \mathrm{m}\left(170 \mathrm{~cm}^{-1}\right)$ is achieved at $7.6 \mu \mathrm{m}$. This wavelength change can be sufficient to measure one or several absorption lines of a molecule.

A narrower spectrum of the source could be desired as some atmospheric gases may have absorption lines with widths less than $1 \mathrm{~cm}^{-1}$. But this is not the case with complex multi-atom molecules that usually have absorption linewidths of more than $10 \mathrm{~cm}^{-1}$ and very narrow spectrum sources are not required. For example, the near infrared laser source with the $8 \mathrm{~cm}^{-1}$ bandwidth was successfully used for spectroscopy of doping agents in [14]. This statement can also be supported by the acetone spectrum in Fig. 5.

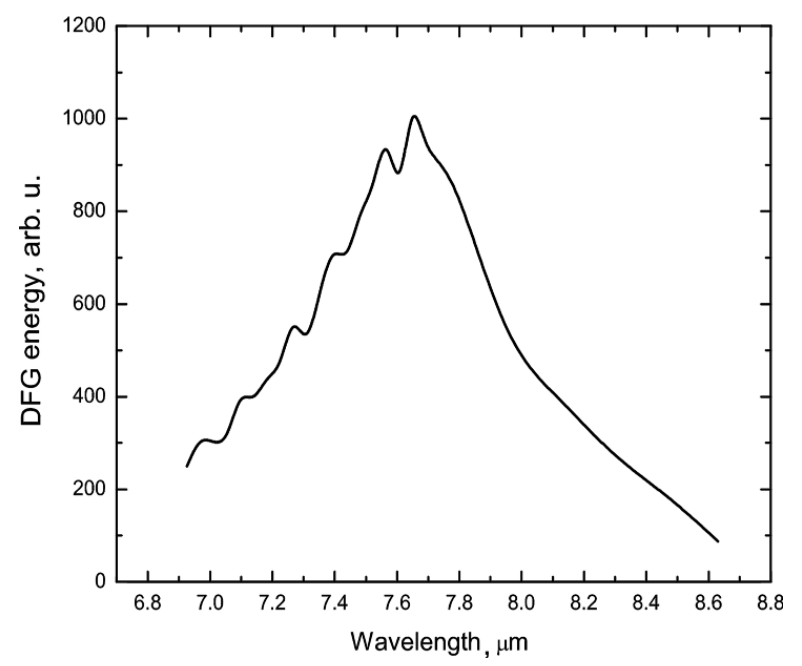

Fig. 6. The tuning range of the DFG wavelength at $170^{\circ} \mathrm{C}$ in $\mathrm{PP}-\mathrm{MgO}: \mathrm{LN}$. 
In summary, a compact mid-IR laser source that consists of the PP-MgO:LN based OPO and subsequent DFG in the $\mathrm{AgGaSe}_{2}$ crystal is described. The average bandwidth of generated radiation is $5 \mathrm{~cm}^{-1}$ in the whole tuning range from 6 to $13 \mu \mathrm{m}$. Although the efficiency of the conversion has been low, the set-up could be easily scaled to higher power and higher efficiency if higher pump energies are available. One of the most attractive features of this source is mid-IR wavelength tuning without change of the PP-MgO : LN crystal temperature. Fast tuning, reasonable bandwidth, and high repetition rate make this source a suitable candidate for mid-IR spectroscopic applications.

\section{References}

[1] S. Haidar and H. Ito, Periodically poled lithium niobate optical parametric oscillator pumped at $0.532 \mu \mathrm{m}$ and use of its output to produce tunable $4.6-8.3 \mu \mathrm{m}$ in $\mathrm{AgGaS}_{2}$ crystal, Opt. Commun. 202, 227-231 (2002).

[2] S. Haidar, Y. Sasaki, E. Niwa, K. Masumoto, and H. Ito, Temperature tuning of 5-12 $\mu \mathrm{m}$ by difference frequency mixing of OPO outputs in a $\mathrm{AgGaS}_{2}$ crystal, J. Phys. D 36, 1071-1074 (2003).

[3] S.C. Pei, S.Y. Tu, and A.H. Kung, Mid-IR generation by difference frequency mixing of two pulsed PPLN OPOs in $\mathrm{ZnGeP}_{2}$, in: Quantum Electronics and Laser Science Conference, 2005, Vol. 2 (Optical Society of America, 2005) pp. 791-793.

[4] K. Suizu, S. Haidar, T. Usami, K. Nakamura, K. Kawase, and H. Ito, Nano-second continuous tunable 35-38 Thz wave generation by the intra-cavity difference-frequency generation (iDFG) method, in: Lasers and Electro-Optics, 2002 (Optical Society of America, 2002) pp. 147-148.

[5] S. Haidar and H. Ito, Injection-seeded optical paramet- ric oscillator for efficient difference frequency generation in mid-IR, Opt. Commun. 171, 171-176 (1999).

[6] K.S. Abedin, S. Haidar, Y. Konno, C. Takyu, and H. Ito, Difference frequency generation of 5-18 $\mu \mathrm{m}$ in a AgGaSe 2 crystal, Appl. Opt. 37, 1642-1646 (1998).

[7] R. Utano and M. J. Ferry, 8-12 $\mu \mathrm{m}$ generation using difference frequency generation in $\mathrm{AgGaSe}_{2}$ of a $\mathrm{Nd}$ : YAG pumped KTP OPO, in: Advanced Solid State Lasers, eds. C. Pollock and W. Bosenberg, Vol. 10 of OSA Trends in Optics and Photonics Series (Optical Society of America, 1997), paper PC11, pp. 82-84.

[8] A. Bianchi and M. Garbi, Down-conversion in the 4-18 $\mu \mathrm{m}$ range with $\mathrm{GaSe}$ and $\mathrm{AgGaSe}_{2}$ nonlinear crystals, Opt. Commun. 30, 122-124 (1979).

[9] S. Haidar, Y. Sasaki, E. Niwa, K. Masumoto, and H. Ito, Electro-optic tuning of a periodically poled $\mathrm{LiNbO}_{3}$ optical parametric oscillator and mixing its output waves to generate mid-IR tunable from 9.4 to $10.5 \mu \mathrm{m}$, Opt. Commun. 229, 325-330 (2004).

[10] C.S. Yu and A.H. Kung, Grazing-incidence periodically poled $\mathrm{LiNbO}_{3}$ optical parametric oscillator, J. Opt. Soc. Am. B 16, 2233-2238 (1999).

[11] D. Roberts, Dispersion equations for nonlinear optical crystals: KDP, $\mathrm{AgGaSe}_{2}$ and $\mathrm{AgGaS}_{2}$, Appl. Opt. 35, 4677-4688 (1996).

[12] R.L. Sutherland, Handbook of Nonlinear Optics, 2nd ed. (Marcel Dekker, 2003).

[13] NIST Chemistry Webbook, http://webbook.nist.gov/ chemistry/.

[14] C. Fischer, R. Bartlome, and M. Sigrist, The potential of mid-infrared photoacoustic spectroscopy for the detection of various doping agents used by athletes, Appl. Phys. B 85, 289-294 (2006).

[15] A. Miklos, C. Kim, W. Hsiang, G. Liang, A. Kung, A. Schmohl, and P. Hess, Photoacoustic measurement of methane concentrations with a compact pulsed optical parametric oscillator, Appl. Opt. 41, 2985-2993 (2002). 


\title{
SKIRTUMINIO DAŽNIO GENERAVIMAS SĄVEIKAUJANT PP-MgO : LN PARAMETRINIO ŠVIESOS GENERATORIAUS SIGNALINEI IR ŠALUTINEI BANGOMS
}

\author{
V. Vaičikauskas ${ }^{a}$, M. Kaučikas ${ }^{\text {a,b }}$, Z. Kuprionis ${ }^{b}$ \\ ${ }^{\text {a }}$ Fizikos institutas, Vilnius, Lietuva \\ ${ }^{\mathrm{b}}$ UAB EKSPLA, Vilnius, Lietuva
}

\section{Santrauka}

Aprašomas skirtuminio dažnio generavimas $\mathrm{AgGaSe}_{2}$ kristale tarp PP-MgO : LN parametrinio šviesos generatoriaus signalinès ir šalutinès bangų. Generuojamos spinduliuotès bangos ilgis yra derinamas nuo 6 iki $13 \mu \mathrm{m}$, o vidutinè jos galia siekia keletą mili- vatų. Aprašyta šaltinio konfigūracija leidžia greitai keisti spinduliuotès bangos ilgi, nekeičiant PP-MgO : LN kristalo temperatūros. Būdingasis generuojamos spinduliuotès spektro plotis yra $5 \mathrm{~cm}^{-1}$, o tai leidžia naudoti ši šaltini sudètingų molekulių spektroskopijai atmosferos sąlygomis. Tai iliustruojama acetono garu pavyzdžiu. 